\title{
Prolonged Complete Response after GEMOX Chemotherapy in a Patient with Advanced Fibrolamellar Hepatocellular Carcinoma
}

\author{
Pauline Gras $^{a} \quad$ Stéphanie Truant ${ }^{b} \quad$ Valérie Boige $^{c}$ \\ Laure Ladrat $^{a} \quad$ Philippe Rougier $^{d} \quad$ François-René Pruvot $^{c}$ \\ Mohamed Hebbar ${ }^{a}$ \\ Departments of ${ }^{\mathrm{a}}$ Medical Oncology and ${ }^{\mathrm{b}}$ Surgery and Transplantation, \\ University Hospital, Lille, 'Department of Oncologic Medicine, Gustave Roussy \\ Institute, Villejuif, and ${ }^{d}$ Department of Digestive Oncology, Georges Pompidou \\ European Hospital, Paris, France
}

\section{Key Words}

Fibrolamellar hepatocellular carcinoma $\cdot$ Healthy liver $\cdot$ Oxaliplatin $\cdot$ Gemcitabine

\section{Abstract}

The only currently validated treatment for advanced hepatocellular carcinoma (HCC) is sorafenib. However, sorafenib has been mainly studied in patients with HCC developed in cirrhotic liver. Chemotherapy might be more suitable for patients with HCC in non-cirrhotic liver. We report the case of a young woman with fibrolamellar HCC in a non-cirrhotic liver, with histologically proven metastatic ganglionary relapse after surgical resection of the primary tumour. Chemotherapy with gemcitabine and oxaliplatin (GEMOX regimen) achieved a complete response without relapse five years after discontinuation of chemotherapy. This exceptional case raises the question of clinical trials specifically designed for patients with HCC in non-cirrhotic liver.

\section{Introduction}

Fibrolamellar hepatocellular carcinoma (HCC) is a rare liver tumour [1]. In contrast to conventional HCC, this tumour occurs in non-cirrhotic liver. It usually affects young adults or adolescents, is characterised by a slow evolution and the lack of increase of $\alpha$-foetoprotein ( $\alpha$-FP) level. Although the treatment mainly consists of surgery, 
metastatic relapse is associated with a poor prognosis [2]. In case of advanced disease, there is no recognised systemic therapy, especially chemotherapy, as a result of the lack of specific trials. We here report the case of a prolonged complete response after GEMOX chemotherapy (gemcitabine-oxaliplatin) in a young woman with metastatic fibrolamellar HCC.

\section{Case Report}

A 25-year-old woman presented with a mass of the right hypochondrium in December 2003. CT scan revealed a large $(10-\mathrm{cm}$ diameter) hypodense and hypervascularised tumour of the left liver lobe. The $\alpha$-FP level was normal. A left hepatectomy was performed in January 2004. The histological analysis demonstrated a typical fibrolamellar HCC. In July 2004, a CT scan revealed coeliac lymph nodes. A hepatic and coeliac lymphadenectomy was performed. Histological analysis confirmed metastatic relapse of the fibrolamellar HCC. In August 2005, mediastinal lymph nodes appeared, and GEMOX chemotherapy was administered: gemcitabine $1,000 \mathrm{mg} / \mathrm{m}^{2}$ on day 1 and oxaliplatin 100 $\mathrm{mg} / \mathrm{m}^{2}$ on day 2 , one cycle every 14 days. Six cycles were performed until November 2005 , allowing to obtain a complete tumoural response. In July 2006, large carotid-jugular and right susclavicular lymph nodes appeared. The CT scan revealed diffuse retroperitoneal and mediastinal lymph nodes. A cervical node was resected. Pathological examination confirmed the relapse of fibrolamellar HCC. GEMOX chemotherapy was restarted. A complete response was observed after 4 cycles. A total of 10 cycles were administered, with a good tolerance, except for a grade II sensitive neuropathy. In March 2012, five years after chemotherapy completion, the complete response is still ongoing.

\section{Discussion}

The only currently validated treatment for advanced HCC is sorafenib, which is used based on the results of two randomised placebo-controlled trials [3, 4]. However, the benefit in terms of overall survival is moderate, nearly 2 to 3 months, with quite significant toxicity. Moreover, the objective response rate is very low (2\%). Although this was not specified, these randomised trials probably enrolled mainly cirrhotic patients given the ratio of underlying cirrhosis usually (50-90\%) observed in patients with HCC [5], and sorafenib is restricted to patients with compensated cirrhosis (Child-Pugh A) [6].

Nearly $5-10 \%$ of HCCs occur in healthy livers without cirrhosis. One particular tumour among these HCCs that develops in healthy liver is fibrolamellar HCC. At advanced stages (locally advanced and/or metastatic), the evolution of fibrolamellar HCC may be prolonged, but the prognosis remains poor [2].

The use of sorafenib in patients with HCC in non-cirrhotic liver highlights two limits. Firstly, as mentioned above, randomised trials on sorafenib did not address this particular group of patients, especially those with fibrolamellar histology which represents a usual exclusion criteria in HCC trials. Secondly, normal liver function could allow more aggressive treatments, such as chemotherapy, which in turn may facilitate surgical treatment (resection or transplantation) in case of tumour downsizing.

Systemic chemotherapy does not have any validated place in the management of patients with HCC, but this results almost partly from its poor tolerance due to cirrhosis [7]. For example, in a phase II trial of docetaxel therapy in patients with advanced HCC, we obtained only one objective response among 15 enrolled patients, which led to the 
termination of the trial [8]. Interestingly, this objective response was observed in the single patient without cirrhosis and allowed liver transplantation. In most of the other patients with cirrhosis, the toxicity was significant. Subsequently, three other patients with HCC in non-cirrhotic livers were treated with docetaxel. An objective response with long-term survival was obtained in all cases [9].

In the present report, we used GEMOX chemotherapy, which had promising results in phase II trials $[10,11]$. To our knowledge, this is the first report showing the complete tumour response of a metastatic fibrolamellar HCC. This complete response was observed from the fourth cycle of chemotherapy and has been maintained for five years. Such a result would probably not have been expected by the use of sorafenib alone.

A downsizing of locally advanced fibrolamellar HCC by chemotherapy might be obtained as well, enabling curative surgery. In a retrospective study on 24 patients with HCC in non-cirrhotic liver, chemotherapy with epirubicin, cisplatin and either 5 -fluorouracile or capecitabine achieved a $22 \%$ objective response rate, allowing surgical resection in two cases [12]. Recently, a complete tumour response after GEMOX chemotherapy was reported in a patient with HCC in a non-cirrhotic liver [13].

This report raises the question of trials specifically designed for patients with HCC in non-cirrhotic liver, particularly fibrolamellar HCC. The value of joining sorafenib to chemotherapy has to be also evaluated. In a randomised phase III trial, doxorubicin plus sorafenib was compared to doxorubicin plus placebo in 96 patients with HCC in cirrhotic liver [14]. The median time to progression (6.4 vs. 2.8 months) and median overall survival (13.7 vs. 6.5 months) were longer in the sorafenib-doxorubicin group. However, these results are not relevant for clinical routine because the doxorubicin-alone arm cannot be considered as a reference.

We are currently planning a randomised phase II trial of sorafenib versus GEMOX chemotherapy in patients with HCC in non-cirrhotic liver.

\section{Disclosure Statement}

The authors have no conflicts of interest to declare. 


\section{References}

1 Ward SC, Waxman S: Fibrolamellar carcinoma: a review with focus on genetics and comparison to other malignant primary liver tumors. Semin Liver Dis 2011;31:61-70.

-2 Katzenstein HM, Krailo MD, Malogolowkin MH, Ortega JA, Qu W, Douglass EC, Feusner JH, Reynolds M, Quinn JJ, Newman K, Finegold MJ, Haas JE, Sensel MG, Castleberry RP, Bowman LC: Fibrolamellar hepatocellular carcinoma in children and adolescents. Cancer 2003;97:2006-2012.

-3 Llovet JM, Ricci S, Mazzaferro V, Hilgard P, Gane E, Blanc JF, de Oliveira AC, Santoro A, Raoul JL, Forner A, Schwartz M, Porta C, Zeuzem S, Bolondi L, Greten TF, Galle PR, Seitz JF, Borbath I, Häussinger D, Giannaris T, Shan M, Moscovici M, Voliotis D, Bruix J; SHARP Investigators Study Group: Sorafenib in advanced hepatocellular carcinoma. N Engl J Med 2008;359:378-390.

4 Cheng AL, Kang YK, Chen Z, Tsao CJ, Qin S, Kim JS, Luo R, Feng J, Ye S, Yang TS, Xu J, Sun Y, Liang H, Liu J, Wang J, Tak WY, Pan H, Burock K, Zou J, Voliotis D, Guan Z: Efficacy and safety of sorafenib in patients in the Asia-Pacific region with advanced hepatocellular carcinoma: a phase III randomised, double-blind, placebo-controlled trial. Lancet Oncol 2009;10:25-34.

-5 Trevisani F, Frigerio M, Santi V, Grignashi A, Bernardi M: Hepatocellular carcinoma in non-cirrhotic liver: a reappraisal. Dig Liver Dis 2010;42:341-347.

-6 Boige V, Barbare JC, Rosmorduc 0: Groupe de travail carcinome hépatocellulaire Prodige-Afef. Use of sorafenib (Nexavar) in the treatment of hepatocellular carcinoma: PRODIGE AFEF recommendations. Gastroenterol Clin Biol 2008;32:3-7.

7 Mulcahy MF: Management of hepatocellular cancer. Curr Treat Options Oncol 2005;6:423-435.

-8 Hebbar M, Ernst O, Cattan S, Dominguez S, Oprea C, Mathurin P, Triboulet JP, Paris JC, Pruvot FR: Phase Il trial of docetaxel therapy in patients with advanced hepatocellular carcinoma. Oncology 2006;70:154158.

-9 Romano 0, Truant S, Sergent-Baudson G, Comet B, Pruvot FR, Hebbar M: Docetaxel therapy for advanced hepatocellular carcinoma developed in healthy liver: report of three cases. J Chemother 2008;20:518520.

10 Taïeb J, Bonyhay L, Golli L, Ducreux M, Boleslawski E, Tigaud JM, de Baere T, Mansourbakht T, Delgado MA, Hannoun L, Poynard T, Boige V: Gemcitabine plus oxaliplatin for patients with advanced hepatocellular carcinoma using two different schedules. Cancer 2003;98:2664-2670.

11 Louafi S, Boige V, Ducreux M, Bonyhay L, Mansourbakht T, de Baere T, Asnacios A, Hannoun L, Poynard T, Taïeb J: Gemcitabine plus oxaliplatin (GEMOX) in patients with advanced hepatocellular carcinoma: results of a phase II study. Cancer 2007;109:1384-1390.

12 Edeline J, Raoul JL, Vauleon E, Guillygomac'h A, Boudjema K, Boucher E: Systemic chemotherapy for hepatocellular carcinoma in non-cirrhotic liver: a retrospective study. World J Gastroenterol 2009;15:713-716.

13 Boschetti G, Walter T, Hervieu V, Cassier P, Lombard-Bohas C, Adham M, Scoazec JY, Dumortier J: Complete response of hepatocellular carcinoma with systemic combination chemotherapy: not to get out the chemotherapy? Eur J Gastroenterol Hepatol 2010;22:1015-1018.

14 Abou-Alfa GK, Johnson P, Knox JJ, Capanu M, Davidenko I, Lacava J, Leung T, Gansukh B, Saltz LB: Doxorubicin plus sorafenib vs doxorubicin alone in patients with advanced hepatocellular carcinoma: a randomized trial. JAMA 2010;304:2154-2160. 